\title{
Recalling radon's recognition
}

\author{
Brett F. Thornton and Shawn C. Burdette look back at the discovery - and the many different names - of \\ element 86.
}

"inc n 1899, Pierre and Marie Curie noted an "induced radioactivity" - left behind by radium, distinct from its own radioactivity. Ernest Rutherford and Robert B. Owens also reported that year on a radioactive substance $\left({ }^{220} \mathrm{Rn}, t_{1 / 2}=55.6 \mathrm{~s}\right)$ emitted by thorium, which they called emanation. In 1900, Friedrich Dorn realized that the Curies had observed a unique substance $\left({ }^{222} \mathrm{Rn}, t_{1 / 2}=3.8 \mathrm{~d}\right)$, similar to emanation. In 1904, André-Louis Debierne found a third radioactive particle; this one produced from actinium $\left({ }^{219} \mathrm{Rn}, t_{1 / 2}=4 \mathrm{~s}\right)$. These were at first regarded as elements and became colloquially known as thorium emanation, radium emanation and actinium emanation, but today we recognize them as radon isotopes. William Ramsay and J. Norman Collie suggested ${ }^{1}$ a unique set of names (exradio, exthorio and exactinio) for these 'elements': "it appears advisable to devise a name which should recall its source, and, at the same time, by its termination, express the radical difference which undoubtedly exists between it and other elements."

The specific -io suffix names were largely ignored, but the concept of amalgamated names resonated within the scientific community. As experiments revealed similarities to the noble gases, Ramsay and Robert Whytlaw-Gray suggested niton $(\mathrm{Nt})$, a name with the noble gas -on suffix, for the luminescent radium emanation. In 1911, the International Committee on Atomic Weights added the 'isotope' niton to their list of elements ${ }^{2}$, inadvertently intertwining the linguistics of isotopes and elements. This was before 1913, the year Moseley showed that each element has a unique atomic number, and Frederick Soddy coined the term 'isotope, so this early misstep is understandable.

Names for the emanations that evoked both the noble gases and the emanations' parent elements eventually appeared, including Marie Curie's suggestion ${ }^{3}$ of radion or radioneon. Eventually, in 1923, IUPAC adopted $^{4}$ the names radon $(\mathrm{Rn})$, thoron $(\mathrm{Tn})$

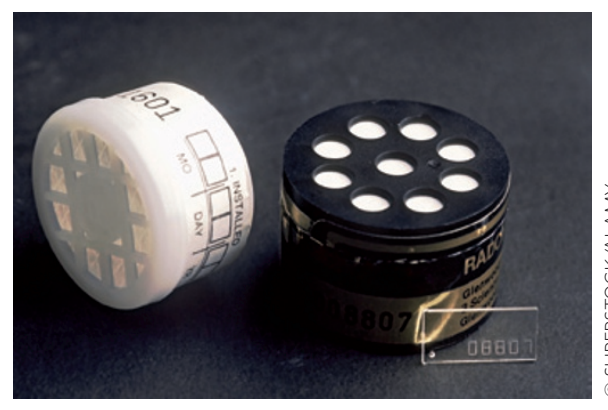

and actinon (An) for the three isotopes; names suggested by Elliott Q. Adams.

An official statement on a name for all three isotopes - that is, a name for the element itself - would take seven more years. In a 1931 paper $^{5}$ that included Marie Curie, Rutherford and Debierne as co-authors, Rutherford's original 1899 element name emanation (Em) was finally formalized, in addition to the three isotope names. Despite this consensus of three early researchers of the element, periodic tables and lists of elements most often chose the name radon - the most stable isotope - instead of emanation. IUPAC's 1957 Nomenclature of Inorganic Chemistry elevated radon from isotope name to element name ${ }^{6}$, an implicit change because only radon appeared on the element list. IUPAC's amended rules stated: "All isotopes of an element should have the same name. For hydrogen the isotope names protium, deuterium and tritium, may be retained, but it is undesirable to assign isotopic names instead of numbers to other elements."

Despite this declaration, radon had been designated an isotope for nearly four decades, and was a poor choice for an element name. Emanation was replaced by the awkward need to specify if the word radon referred to the element or the isotope. Using radon as the element name also muddled history. Dorn, who identified radium emanation (a specific isotope of radon) is today often mistakenly credited with discovering the element radon. Dorn's work even cited Rutherford and Owens' earlier discovery of thorium emanation, the radon isotope thoron.
Thoron, unlike radon, requires no such clarification, and ${ }^{220} \mathrm{Rn}$ is routinely called thoron today. Thoron is far easier to say than 'radon-two-twenty', perhaps explaining why the annual count of scientific papers mentioning thoron has increased over twentyfold since thoron was 'disallowed' in 1957.

Distinguishing between ${ }^{222} \mathrm{Rn}$ (the isotope called 'radon') and ${ }^{220} \mathrm{Rn}$ (thoron) is not of idle linguistic and historic interest. ${ }^{222} \mathrm{Rn}$ can persist indoors, whereas the shortlived thoron cannot. Not all home radon detectors (pictured) are sensitive to thoron, and thoron-sensitive detectors must be placed with care because thoron does not travel far from its source. ${ }^{222} \mathrm{Rn}$ tests cannot necessarily rule out the presence of thoron ${ }^{7}$, which occasionally leads to uncertainties in radon risk assessments.

Very few isotopes hold special names in modern chemistry: deuterium, tritium and thoron exist as near-element footnotes on the periodic table. Actinon has nearly vanished from the scientific literature, likely due to its short half-life and comparatively negligible health impacts. In 1948, the fourth natural isotope of radon was found $\left({ }^{218} \mathrm{Rn}\right.$, $t_{1 / 2}=35 \mathrm{~ms}$ ). No one, apparently, thought of naming this final natural radon isotope - a $\beta$-decay product of ${ }^{218} \mathrm{At}$ - 'astaton'.

\section{BRETT F. THORNTON ${ }^{1}$ and SHAWN}

C. BURDETTE2 are in ${ }^{1}$ Department of Geological Sciences (IGV) and Bolin Centre for Climate Research, Stockholm University, 10691 Stockholm, Sweden; ${ }^{2}$ Department of Chemistry and Biochemistry, Worcester Polytechnic Institute, Worcester, Massachusetts 01609-2280, USA. e-mail: brett.thornton@geo.su.se; scburdette@WPI.EDU

\section{References}

1. Ramsay, W. \& Collie, J. N. Proc. Roy. Soc. Lond. 73, 470-476 (1904)

2. Clarke, F., Thorpe, T., Ostwald, W. \& Urbain, G. J. Am. Chem. Soc. 33, 1639-1642 (1911)

3. Wilson, D. Rutherford: Simple Genius (MIT Press, 1983).

4. Aston, F. W. et al. J. Am. Chem. Soc. 45, 867-874 (1923).

5. Curie, M. et al. J. Am. Chem. Soc. 53, 2437-2450 (1931).

6. Bassett, H. et al. J. Am. Chem. Soc. 82, 5523-5544 (1960).

7. Janik, M. et al. J. Radiat. Res. 54, 597-610 (2013).
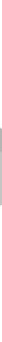